\title{
Improvement of Polypropylene Adhesion by Kraft Lignin Incorporation
}

\author{
Rogério Ramos de Sousa Junior ${ }^{a, b} \mathbb{D}$, Julia Rocha Gouveia ${ }^{a}$, Amanda Martins Nacas ${ }^{a}$,
}

Lara Basilio Tavares ${ }^{a}$, Nathalie Minako Ito ${ }^{a}$,Erivaldo Nascimento de Moura ${ }^{b}$, Felipe Ariel Gaia ${ }^{b}$,

\author{
Robson Fernando Pereira ${ }^{b}$, Demetrio Jackson dos Santos ${ }^{a * \mathbb{D}}$
}

\author{
${ }^{a}$ Centro de Engenharia, Modelagem e Ciências Sociais Aplicadas, Universidade Federal do ABC, Santo \\ André, SP, Brasil \\ ${ }^{b}$ Faculdade de Tecnologia Mauá, Mauá, SP, Brasil
}

Received: February 18, 2018; Revised: December 05, 2018; Accepted: February 03, 2019

\begin{abstract}
Low surface energy and poor adhesion are well-known characteristics of polypropylene (PP). Surface treatments such as plasma, corona, and laser are usually applied to overcome these limitations. However, current studies highlight the incorporation of hydrophilic or amphiphilic polymers into hydrophobic low-surface-energy polymers as an alternative for increasing surface energy and thus improving adhesion. Lignin could be a promising amphiphilic polymer for use in increasing surface energy. In this work, PP/kraft lignin composites were obtained by incorporating up to $5 \mathrm{wt} \%$ of kraft lignin (KL) into a PP matrix. Corona treatment was applied to pristine PP and composites surfaces. Contact angle measurements and peeling tests were carried out to investigate the effects of KL incorporation and corona treatment on the surface energy and the mechanical strength of adhesion. Differential scanning calorimetry (DSC) was used to evaluate the PP's crystallinity index and recrystallization temperature and to dismiss their effects on the surface energy changes. Scanning electron microscopy (SEM) was applied to investigate the lignin dispersion. The results show that KL incorporation has potential as a method to improve the surface energy of PP, improve its poor adhesion, and enhance the effects of corona treatment.
\end{abstract}

Keywords: Adhesion, lignin, surface energy, contact angle.

\section{Introduction}

Polypropylene (PP) can be processed in several ways and is widely used in packaging. However, PP has an apolar and chemically stable surface, which means that it is a hydrophobic material with low surface energy. Consequently, PP is well known for its poor adhesion properties ${ }^{1,2}$, which can compromise its adhesion to other layers of flexible laminated packaging.

However, several techniques can be employed to improve the adhesion of hydrophobic films, such as Corona ${ }^{3}$, plasma $^{4}$, and laser ${ }^{5}$ treatments. Corona discharge treatment (CDT) has been widely used on PP films, particularly for the possibility of coupling it with extrusion lines and working at room temperature ${ }^{6}$. CDT consists of applying a non-uniform high-voltage beam from a thin electrode to the surface of the polymeric material, with typical voltages in the range of 10 to $25 \mathrm{kV}$ and frequencies of 10 to $40 \mathrm{kHz}^{7,8}$. However, for dielectric materials, the technique is mostly limited to films with low thickness since the discharge current decreases drastically as a function of the thickness ${ }^{9}$. This process oxidizes the polymer surface by adding functional polar groups to the upper layer, including hydroxyl $(\mathrm{OH})$, carbonyl $(\mathrm{C}=\mathrm{O})$, and carboxylic $(\mathrm{COOH})$ groups. This

*e-mail: demetrio.santos@ufabc.edu.br mechanism increases the superficial energy of the material, aside from improving the chemical bonding and increasing the roughness, which promote $\mathrm{PP}$ adhesion ${ }^{3,8}$.

Hydrophilization has emerged as an important method to improve the surface energy of hydrophobic polymers. In this process, hydrophilic or amphiphilic materials are blended with hydrophobic materials ${ }^{10}$. This method of blending different polymers to improve the adhesion of polymer films avoids an additional stages in polymer processing, such as surface treatment, thus reducing the costs of processing and equipment ${ }^{11}$. In this regard, the lignin appears to be a promising alternative to increase the surface energy of hydrophobic polymers ${ }^{12}$.

Lignin is a tridimensional amorphous biopolymer that is mainly composed of aromatic moieties that contain different functional groups, such as carboxyl, carbonyl, methoxyl, and hydroxyl ${ }^{13-15}$. It has been considered as a primary renewable source of aromatics, representing $30 \%$ of all non-fossil organic carbon on Earth ${ }^{16,17}$. Lignin can be obtained from chemical processes such as the kraft process from the pulp and paper industry, where it is treated as waste. Kraft lignin (KL) has a high amount of aromatic hydroxyl groups, which increases its water absorption ${ }^{18}$. The incorporation of KL into hydrophobic polymers can therefore reduce its hydrophobicity and contribute to the efficiency of methods such as CDT. Furthermore, lignin incorporation into polymeric materials 
would be highly beneficial in an economic and environmental sense since it is a readily available, renewable, and nonedible industrial byproduct. Moreover, the application of natural and renewable raw materials on industrial product developments can support the achievement of sustainable societies and contribute to solve problems related to petroleum based products ${ }^{19-21}$. In addition, composites performance can be improved by proper material selection, which is crucial for achieve sustainable designs and product properties ${ }^{22}$. In this context, recent methodologies were developed for material selection, which are based on analytical hierarchy process (AHP) and might be applied to solve multi-criteria decision-making (MCDM) problems ${ }^{19,20}$. These novel methodologies consider evaluation of experts in the field and were successfully applied on natural fiber composites and others ${ }^{23-25}$.

In this work, up to $5 \mathrm{wt} \%$ of KL was incorporated into PP matrix to improve its adhesion properties. Two types of KL were used: acid (AC) and alkaline (ALK) KL, which differ in the amount of hydroxyl level, molar mass, and $\mathrm{pH}$. Typically, AC has a higher hydroxyl level due to purification process applied to reduce the ALK $\mathrm{pH}$. The results indicate that KL has potential as an additive to enhance the adhesion of low-surface-energy polymers and to increase the efficiency of the superficial oxidation of PP by corona treatment.

\section{Materials and Methods}

PP homopolymer with a density of $0.905 \mathrm{~g} / \mathrm{cm}^{3}$ and commercially designated as $\mathrm{H} 503 \mathrm{HS}$ was supplied by Braskem (Triunfo/Brazil). Technical grade AC and ALK KLs (eucalyptus - hardwood) were kindly supplied by Suzano Papel e Celulose (Suzano/Brazil) and were obtained as byproduct of pulping and paper manufacturing. $\mathrm{AC}$ has a $\mathrm{pH}$ of 3.5 ( $2 \%$ ash content), molecular mass of $2.448 \mathrm{~g} / \mathrm{mol}$, hydroxyl content of $4.28 \mathrm{mmolOH} / \mathrm{g}$ and syringyl $(\mathrm{S})$ : guaiacyl $(\mathrm{G})$ : p-hydroxyphenyl $(\mathrm{H})$ ratio of 46:50:4. ALK has a $\mathrm{pH}$ of 8.2 ( $2 \%$ ash content), molecular mass of $3.127 \mathrm{~g} / \mathrm{mol}$, hydroxyl content of $3.79 \mathrm{mmolOH} / \mathrm{g}$ and $\mathrm{S}: \mathrm{G}: \mathrm{H}$ ratio of 47:49:4.

The incorporation of KL into PP was carried out in a melted state using a Brabender Plastograph EC torque rheometer with a W50ET mixer. The processing was done with a cycle time of $8 \mathrm{~min}$ at $190{ }^{\circ} \mathrm{C}$, and the lignin was incorporated after 4 minutes (half the time to obtain molten PP). Table 1 shows the sample names and their compositions. Films with a thickness of $200 \mu \mathrm{m}$ were obtained in a heated press at $190{ }^{\circ} \mathrm{C}$ and pressure of $0.1 \mathrm{MPa}$ for 5 minutes. "CDT" was added to the sample names to identify specimens subjected to corona treatment in addition to the nomenclature presented in Table 1.
Table 1. Sample nomenclatures and compositions.

\begin{tabular}{lccc}
\hline Name & PP (\%) & AC (\%) & ALK (\%) \\
\hline PP & 100 & - & - \\
PP_AC_1 & 99 & 1 & - \\
PP_AC_2 & 98 & 2 & - \\
PP_AC_5 & 95 & 5 & - \\
PP_ALK_1 & 99 & - & 1 \\
PP_ALK_2 & 98 & - & 2 \\
PP_ALK_5 & 95 & - & 5 \\
\hline
\end{tabular}

\subsection{Corona discharge treatment (CDT)}

CDT was performed at a fixed velocity of approximately $1.67 \mathrm{~m} / \mathrm{min}$ with a gap of $3 \mathrm{~mm}$ between the film and electrode. The unit energy used in the treatment was $16.8 \mathrm{~kJ} / \mathrm{m}^{2}$ according to Equation (1):

$$
E=\frac{P}{u L}
$$

Where $P$ is the discharge power $(\mathrm{kJ} / \mathrm{s}), u$ is the linear velocity of the film $(\mathrm{m} / \mathrm{s})$ and $L$ is the length of the discharge electrode $(\mathrm{m})^{3}$.

\subsection{Contact angle}

To evaluate the surface energy of the polymer films, contact angle measurements were performed on the films with AC and ALK addition with and without CDT, and the results were compared to those of neat PP. The measurements were performed by the sessile drop method in a drop shape analyzer DSA100 with two different liquids: distilled water and diiodomethane. The test drop volume was $10 \mu \mathrm{L}$, and the measurement was repeated five times for each liquid.

The film surface energy $\left(\gamma_{S L}\right)$ is estimated using the Fowkes model, which was developed from the interfacial free energy model:

$$
\gamma_{S L}=\gamma_{S}+\gamma_{S L}-2 \sqrt{\gamma_{S}^{d} \gamma_{L}^{d}}-2 \sqrt{\gamma_{S}^{p} \gamma_{L}^{p}}
$$

This model combines polar and dispersive interactions between solid and liquid surfaces. $\gamma_{S}^{p}$ and $\gamma_{S}^{d}$ are the polar and dispersive components of surface energy, respectively, while $\gamma_{L}^{p}$ and $\gamma_{L}^{d}$ are the same components for the surface tension of the liquid. Once the liquid surface energy and contact angle are known, the polar and dispersive contribution can be calculated using Equation (3):

$$
\gamma_{L}(1+\cos \theta)=2 \sqrt{\gamma_{S}^{d} \gamma_{L}^{d}}+2 \sqrt{\gamma_{S}^{p} \gamma_{L}^{p}}
$$

At least two liquids with known surface tension values are required to estimate the polar and dispersive components 
of the total surface energy. Distilled water and diiodomethane were used, and the respective surface tensions for each component are shown in Table 2.

\subsection{Peel test}

Peel tests were performed to evaluate the practical adhesion of neat PP and KL-containing films (with and without CDT) bonded to aluminized bioriented polypropylene (BOPP) layer. The samples were prepared by manual lamination using a polyurethane (PU)-based bicomponent adhesive supplied by Henkel with a 10:8 ratio (stoichiometric condition concerning NCO:OH ratio) of Loctite ${ }^{\circledR}$ Liofol ${ }^{\circledR}$ LA 9526 CP-22 to LA 9729 (polyol and MDI containing prepolymer), which were dissolved in ethyl acetate with a $50 \%$ proportion. PP or PP_KL films were bonded to an aluminized surface of BOPP film by PU adhesive with a thickness of $20 \mu \mathrm{m}$. The samples were prepared according to the method presented by Ito et. $a l^{26}$.

The tests were performed on an EMIC DL-200 peel tester according to ASTM Standard F904. The $90^{\circ}$ peel tests were carried out at a speed of $0.280 \mathrm{~m} / \mathrm{min}$ with a $100-\mathrm{N}$ load cell. The BOPP and PP film edges were secured by clamps in the peel tester, and the tests were performed by pulling a 50-mm length of the PP from the BOPP film at an angle of $90^{\circ}$ between the films and the direction of applied force. The test was repeated five times for each condition.

\subsection{Fourier transform infrared spectroscopy (FTIR)}

FTIR analyses were performed to verify the presence of PU adhesive residues in the PP_KL and BOPP films (aluminum surface). The results indicate which type of failure occurred during the adhesive strength test. The analyses were performed using Perkin Elmer Varian 660 equipment in attenuated total reflection (ATR) mode. A total of 16 scans were performed from 4000 to $600 \mathrm{~cm}^{-1}$ with a resolution of $4 \mathrm{~cm}^{-1}$.

\subsection{Differential scanning calorimetry (DSC)}

DSC analyses were performed to evaluate the effect of KL addition on the crystallinity index of PP and the thermal behavior of the blends. Tests were carried out using TA Q200 equipment in accordance with ASTM D3418. An initial heating ramp from 35 to $200{ }^{\circ} \mathrm{C}$ was applied to eliminate the material thermal history, followed by a cooling ramp to $-50{ }^{\circ} \mathrm{C}$ and a third ramp from - 50 to $200{ }^{\circ} \mathrm{C}$, where the thermal properties of the samples were evaluated. The

Table 2. Surface tension components for distilled water and diiodomethane.

\begin{tabular}{lcc}
\hline Surface tension & Water & Diiodomethane \\
\hline Total $(\mathbf{m N} / \mathbf{m})$ & 72.8 & 50.8 \\
Polar $(\mathbf{m N} / \mathbf{m})$ & 51.0 & 0 \\
Dispersive $(\mathbf{m N} / \mathbf{m})$ & 21.8 & 50.8 \\
\hline
\end{tabular}

analyses were carried out with an approximate mass of $10 \mathrm{mg}$ in an aluminum container. All heating and cooling steps were performed at controlled rates of $10{ }^{\circ} \mathrm{C} / \mathrm{min}$ and a nitrogen flow of $50 \mathrm{~mL} / \mathrm{min}$.

\section{Results and Discussion}

\subsection{Free surface energy}

Table 3 presents the contact angle measurements. Pure PP presented the highest contact angle measured (i.e., the lowest calculated surface energy; Figure 1). KL incorporation in the PP decreased the contact angles for all tested conditions. The polar contribution to surface energy, which is mainly obtained by the contact angle measured with water, was generally more affected by AC incorporation than ALK addition. Such behavior can be explained by the higher content of polar groups $(\mathrm{OH})$ in the AC than in ALK.

Sample containing $1 \mathrm{wt} \% \mathrm{AC}$ (without CDT) presented a pronounced increase in surface energy, from $31.93 \mathrm{mN} / \mathrm{m}$ to $40.44 \mathrm{mN} / \mathrm{m}$. However, a higher concentration of AC caused a reduction in surface energy, in comparison with $\mathrm{PP} \mathrm{AC}_{-} 1$. Incorporation of ALK slightly and stepwise increased the surface energy. ALK (pH 8.2) has a predominant hydrophilic behavior and partial water solubility, which might justify this behavior. Otherwise, despite its higher $\mathrm{OH}$ content, $\mathrm{AC}(\mathrm{pH} 3.5)$ presents amphiphilic behavior and poor water solubility, due to its combination of aromatic and aliphatic bridges and a variety of oxygenated moieties ${ }^{27}$.

CDT-treated samples presented the same trend as untreated specimens, with KL incorporation providing higher surface energy. However, some differences can be pointed out in comparison to non-treated conditions: i) the optimal $\mathrm{KL}$ concentration increased to a region close to $2 \mathrm{wt} \%$ for both types of KL; ii) ALK generated the highest surface energy value; and iii) the contact angle strongly increased for $5 \mathrm{wt} \%$ with both types of $\mathrm{KL}$ in comparison to other lignin-containing and corona-treated samples. The results revealed a synergistic effect between KL incorporation and corona treatment, which resulted in higher values of surface energy and could lead to energy savings by using corona treatment due to reductions in time or energy level.

\subsection{Adhesive strength}

A proper discussion of the peel strength results requires a previous elucidation of the failure type. PU cohesive failure is used to assess the adhesive properties, while adhesive failure is an indirect assessment of adhesive interactions between the substrate and adhesive. Lastly, substrate failure can be used to verify the influence of joint components on the strength.

Figure 2 shows the FTIR spectra from the aluminized surface of BOPP and PP or PP_KL (without CDT treatment) composite surfaces after the peel test, which were previously bonded using PU adhesive. As shown in Figure 2, peaks 
Table 3. Contact angle values using water and diiodomethane.

\begin{tabular}{|c|c|c|c|c|c|}
\hline \multirow[t]{2}{*}{ Material } & \multicolumn{2}{|c|}{ Contact angle $\left({ }^{\circ}\right)$} & \multirow[t]{2}{*}{ Material } & \multicolumn{2}{|c|}{ Contact angle $\left({ }^{\circ}\right)$} \\
\hline & Water & Diiodomethane & & Water & Diiodomethane \\
\hline$P P$ & $107.22 \pm 2.70$ & $56.70 \pm 0.96$ & $P_{-} P_{C D T}$ & $79.02 \pm 2.90$ & $49.68 \pm 2.69$ \\
\hline$P P_{-} A C_{-} 1$ & $91.42 \pm 1,34$ & $48.88 \pm 1.74$ & $P P_{-} A C_{-}{ }_{-}$CDT & $71.92 \pm 1.94$ & $51.38 \pm 1.69$ \\
\hline$P P \_A C \_2$ & $92.42 \pm 0.96$ & $51.80 \pm 1.25$ & $P P \_A C \_2 \_C D T$ & $65.98 \pm 1.15$ & $49.86 \pm 1.28$ \\
\hline$P P \_A C \_5$ & $92.46 \pm 4.47$ & $51.84 \pm 1.83$ & $P P \_A C \_5 \_C D T$ & $72.28 \pm 1.03$ & $54.86 \pm 0.99$ \\
\hline$P P \_A L K \_1$ & $97.86 \pm 1.26$ & $56.80 \pm 0.70$ & $P P \_A L K \_1 \_C D T$ & $74.99 \pm 1.11$ & $51.91 \pm 2.60$ \\
\hline$P P_{-} A L K_{-} 2$ & $96.42 \pm 0.86$ & $56.00 \pm 0.96$ & $P P \_A L K \_2 \_C D T$ & $59.78 \pm 0.87$ & $51.32 \pm 1.35$ \\
\hline$P P \_A L K \_5$ & $95.58 \pm 1.47$ & $54.34 \pm 0.75$ & $P P \_A L K \_5 \_C D T$ & $73.14 \pm 1.28$ & $52.94 \pm 1.66$ \\
\hline
\end{tabular}

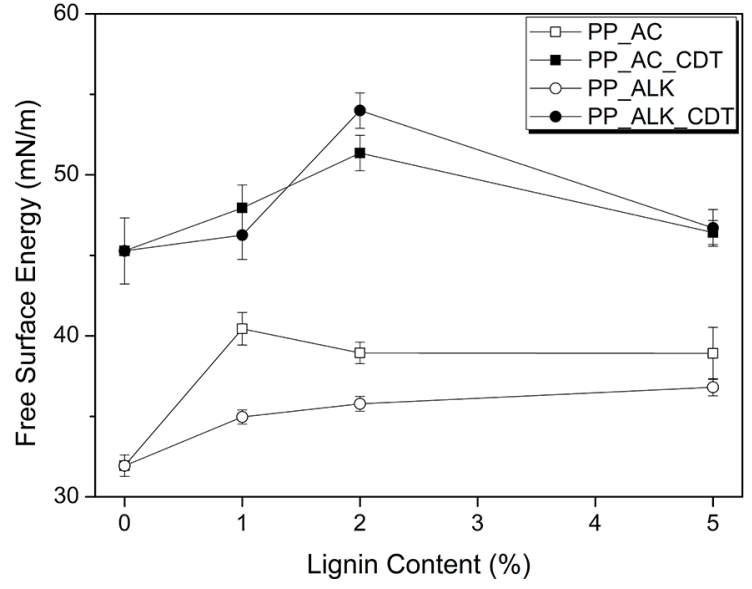

Figure 1. Surface free energy as a function of lignin concentration (AC and ALK) with and without surface treatment

assigned to PU groups are present on the aluminized BOPP surface after the peel test. The peaks at $1725 \mathrm{~cm}^{-1}$ and $3330 \mathrm{~cm}^{-1}$ are related to $\mathrm{C}=\mathrm{O}$ and $\mathrm{NH}$ groups obtained during $\mathrm{PU}$ polymerization ${ }^{28}$. The spectra related to PP or PP_KL composite samples do not contain such peaks related to $\mathrm{PU}$ groups, which indicates the absence of PU on these surfaces. Thus, the results indicate adhesive failure during the peel test; i.e., PU detached from PP or PP_KL films.

Concerning corona-treated samples, previous work revealed that Al-metalized BOPP layers presented substrate failure in peel tests with loading of $120 \mathrm{~N} / \mathrm{m}$ or higher ${ }^{26}$. Table 4 presents the average peel strength values. Coronatreated samples provided average peel strength higher than $126.12 \mathrm{~N} / \mathrm{m}$, which suggest that Al substrate failure of these peel specimens as well according to Ito $e t$. $a l^{26}$.

KL-containing samples (without CDT) developed higher peel strength, in comparison with neat PP. No significant difference was observed between both types of KL regarding peel strength when taking the error involved in the experiments into consideration. KL addition increased the peeling strength, which is in agreement with contact angle measurements since KL incorporation also increased the surface energy, and adhesive failure was verified. There was some divergence between the surface energy and peel strength evolution as a function of KL content. This can be explained by the limitations of the contact angle measurement and peel test, which can only assess the adhesion strength indirectly.

Since $\mathrm{Al}$ cohesive failure was assumed, the peel results for CDT-treated samples are related to the KL incorporation effect on the Al layer strength. KL addition also increased the peel strength of CDT-treated adhesively bonded joints. A concentration of $1 \mathrm{wt} \% \mathrm{KL}$ generated the highest peel strength values. KL incorporation could thus be a tool for improving CDT efficiency when applied to PP surfaces, which would reduce the required corona energy level or obtain higher surface energy for the same discharge level.

\subsection{Differential scanning calorimetry (DSC)}

The polymer crystallization index or degree strongly influences thermoplastic adhesion, in which adhesive interactions are usually developed by the amorphous phase of such polymers. In this context, a decrease in the degree of crystallization by KL incorporation could contribute to the increased peel strength. DSC was used to investigate the effect of lignin incorporation on the melting temperature $\left(\mathrm{T}_{\mathrm{m}}\right)$, recrystallization temperature $\left(\mathrm{T}_{\mathrm{c}}\right)$, glass transition temperature $\left(\mathrm{T}_{\mathrm{g}}\right)$, and degree of crystallization $\left(\chi_{c} \%\right)$. The results are shown in Table 5. The degree of crystallinity of PP was calculated according to Equation (4):

$$
X_{c}(\%)=\frac{\Delta H_{m}}{\Delta H^{\circ}{ }_{m}} \times \frac{1}{f} \times 100
$$

Where $\chi_{c}$ is the degree of crystallinity (\%), $\Delta H_{m}$ is the enthalpy of fusion of different blends, $\Delta H^{o}{ }_{m}$ is the enthalpy of fusion of $100 \%$ crystalline PP $(207 \mathrm{~J} / \mathrm{g})^{29}$, and $f$ is the PP fraction in blends composition.

Figure 3 shows the thermograms of the second heating and cooling cycles for PP and PP_KL. The addition of lignin shifts and slightly broadens both the melting and crystallization peaks. Only one glass transition temperature was found for PP_KL. It is well established that the presence of only one $\mathrm{T}_{\mathrm{g}}$ is considered to indicate homogeneity at the segmental level and therefore blend miscibility ${ }^{30}$. However, this general rule cannot be correctly applied to this system. $\mathrm{T}_{\mathrm{g}}$ of lignin is usually within the range of $110-160{ }^{\circ} \mathrm{C}^{31}$. 
a)

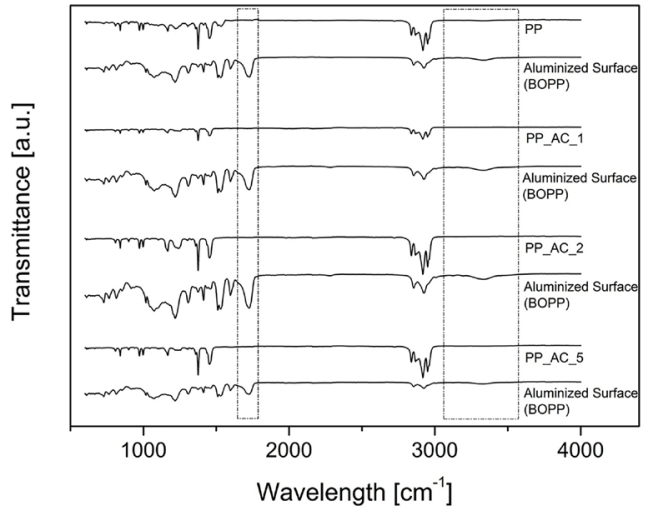

c)

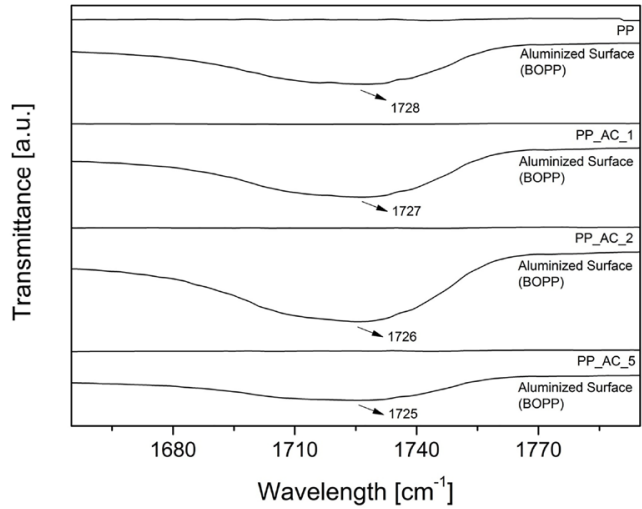

e)

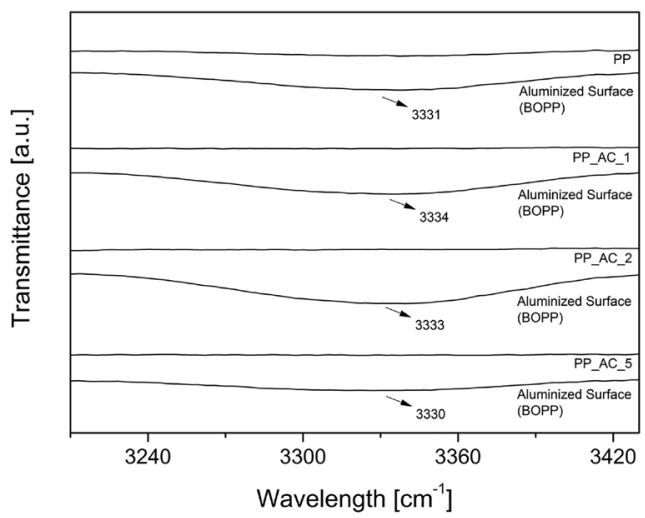

b)

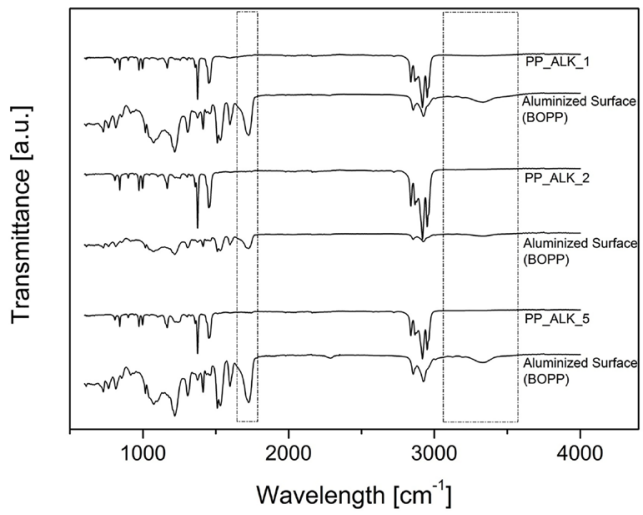

d)

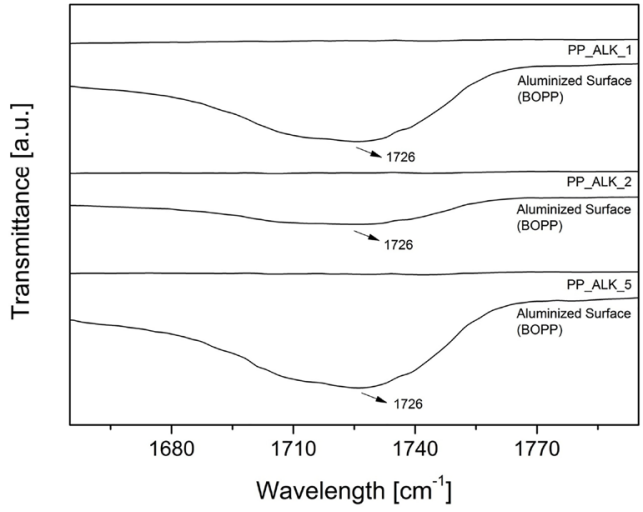

f)

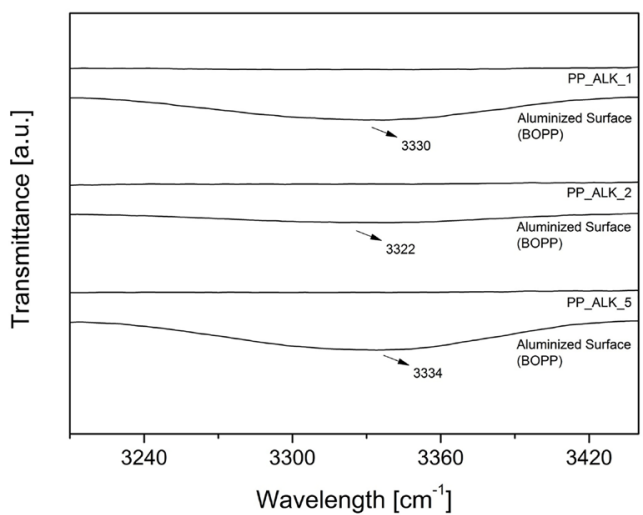

Figure 2. FTIR spectra for PP films with (a) AC and (b) ALK (without CDT) compared to BOPP after peel strength. Amplifications of the bands of $1725 \mathrm{~cm}^{-1}$ (c and d) and $3330 \mathrm{~cm}^{-1}$ (e and f) for AC and ALK, respectively

Table 4. Peel strength values for PP and PP KL films.

\begin{tabular}{|c|c|c|c|}
\hline & Average Strength $(\mathrm{N} / \mathrm{m})$ & & Average Strength $(\mathrm{N} / \mathrm{m})$ \\
\hline$P P$ & $8.73 \pm 0.84$ & PP_CDT & $146.23 \pm 34.38$ \\
\hline$P P_{-} A C_{-} 1$ & $10.61 \pm 0.57$ & $P P \_A C \_1 \_C D T$ & $173.47 \pm 2.304$ \\
\hline PP_AC_2 & $8.91 \pm 0.91$ & $P P_{-} A C_{-}{ }_{2} C D T T$ & $149.66 \pm 1.23$ \\
\hline PP_AC_5 & $12.67 \pm 1.95$ & $P P_{-} A C_{-} 5 \_C D T$ & $139.98 \pm 0.809$ \\
\hline$P P \_A L K \_1$ & $10.50 \pm 1.28$ & $P P \_A L K \_1 \_C D T$ & $169.85 \pm 0.505$ \\
\hline$P P \_A L K \_2$ & $9.38 \pm 1.41$ & $P P \_A L K \_2 \_C D T$ & $164.54 \pm 1.292$ \\
\hline$P P_{-} A L K \_5$ & $9.08 \pm 0.99$ & PP_ALK_5_CDT & $126.12 \pm 2.052$ \\
\hline
\end{tabular}


Table 5. Tm $\left({ }^{\circ} \mathrm{C}\right)$, $\operatorname{Tm}\left({ }^{\circ} \mathrm{C}\right)$, degree of crystallinity $(\%)$ and $\operatorname{Tg}\left({ }^{\circ} \mathrm{C}\right)$ for pure PP and PP/lignin blends.

\begin{tabular}{lcccc}
\hline & Tm $\left({ }^{\circ} \mathbf{C}\right)$ & Tg $\left({ }^{\circ} \mathbf{C}\right)$ & Tc $\left({ }^{\circ} \mathbf{C}\right)$ & Crystallinity Degree $(\%)$ \\
\hline PP & 164.58 & -5.69 & 115.30 & 50.77 \\
PP_AC_1 & 166.00 & -3.16 & 115.26 & 51.92 \\
PP_AC_2 & 165.44 & -3.96 & 114.32 & 51.37 \\
PP_AC_5 & 166.32 & -3.70 & 114.18 & 49.02 \\
PP_ALK_1 & 166.71 & -5.04 & 115.24 & 51.53 \\
PP_ALK_2 & 166.53 & -5.65 & 114.78 & 51.71 \\
PP_ALK_5 & 166.88 & -3.61 & 114.14 & 48.31 \\
\hline
\end{tabular}
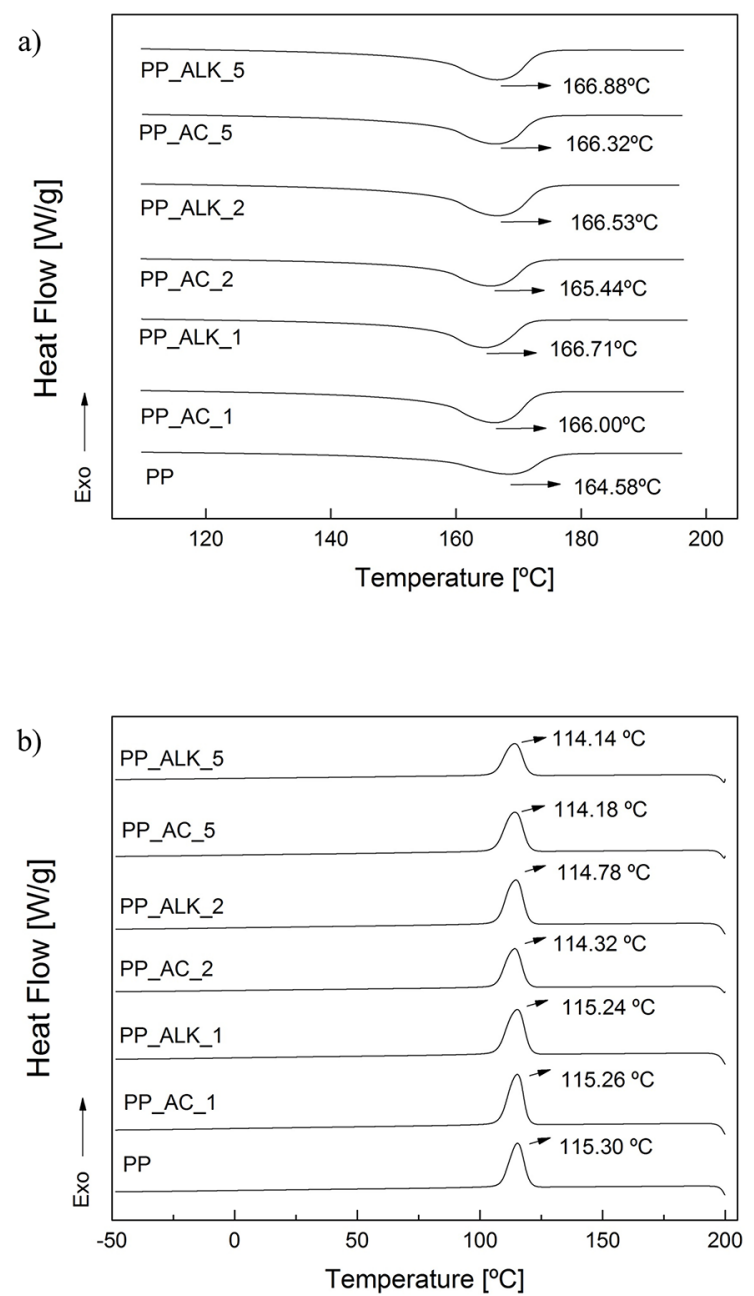

Figure 3. DSC curves for all PP and PP/Lignin blends (a) Melt endotherm obtained during second heating scan (b) Non-isothermal crystallization peak obtained during the cooling ramp

Moreover, lignin stiff molecule hinders $\mathrm{T}_{\mathrm{g}}$ measurements when blended or diluted in other polymers ${ }^{30}$. Therefore, the $\mathrm{T}_{\mathrm{g}}$ associated with the lignin phase of $\mathrm{PP}$ KL could not be determined, which was probably due to the overlap of $\mathrm{T}_{\mathrm{g}}$ of KL with the large PP melt endotherm.

The degree of crystallization was increased by the incorporation of both types of KL at concentrations of up to
$2 \mathrm{wt} \%$. However, the highest KL content presented a slight decrease in the degree of crystallization. Lignin might act as heterogeneous nucleating agent in thermoplastic polymers ${ }^{32}$. The nucleating agent effect of $1 \%$ lignin incorporation has been demonstrated for poly(3-hydroxybutyrate) $(\mathrm{PHB})^{33}$. Similar to this study, blends of PP and lignin have previously exhibited an increase in crystallinity upon lignin incorporation ${ }^{34}$. These findings suggest that lignin favors crystallization at small amounts, but at higher content, its amorphous structure overcomes the heterogeneous nucleation effect, and a lower degree of crystallinity is achieved. Nevertheless, no meaningful changes on crystallinity degree were found for all lignin contents, as listed in Table 5. In addition, higher degrees of crystallization should reduce the peel strength due to the decrease in the amorphous phase content, and this correlation is not observed when comparing DSC and peel strength results (Table 4 and Table 5). Therefore, the crystallinity degree cannot be considered to influence the peel strength results, which strengths our arguments that there is an increase in surface energy due to lignin addition. Moreover, the investigation of the thermal behavior of $\mathrm{PP} /$ lignin blends are of uttermost importance for further technological applications.

\subsection{Scanning electron microscopy (SEM)}

Scanning electron micrographs were obtained to determine whether phase separation occurred between KL and PP phases for the KL contents tested. A lignin rich phase, as consequence of KL aggregation or phase separation, might act as stress concentration factor and low cohesive strength regions, which could result into early failure of flexible laminate. Figure 4 shows the micrographs of AC_KL and a cut surface of PP_AC. The micrographs revealed an absence of patterns related to phase separation. As shown in Figure 4a, AC_KL presented an irregular colloidal shape, which cannot be identified in AC-containing PP. Besides the well-known immiscibility between $\mathrm{PP}$ and $\mathrm{KL}^{35}$, the results pointed out an absence of KL phase, which demonstrates good dispersion between the phases. The same behavior was verified for ALK-containing samples. Results are in agreements with previous works, in which lignin aggregation were verified for concentration of $20 \mathrm{wt} \%$ into $\mathrm{PP}^{34}$, or $10 \%$ into $\mathrm{PBAT}^{36}$. 

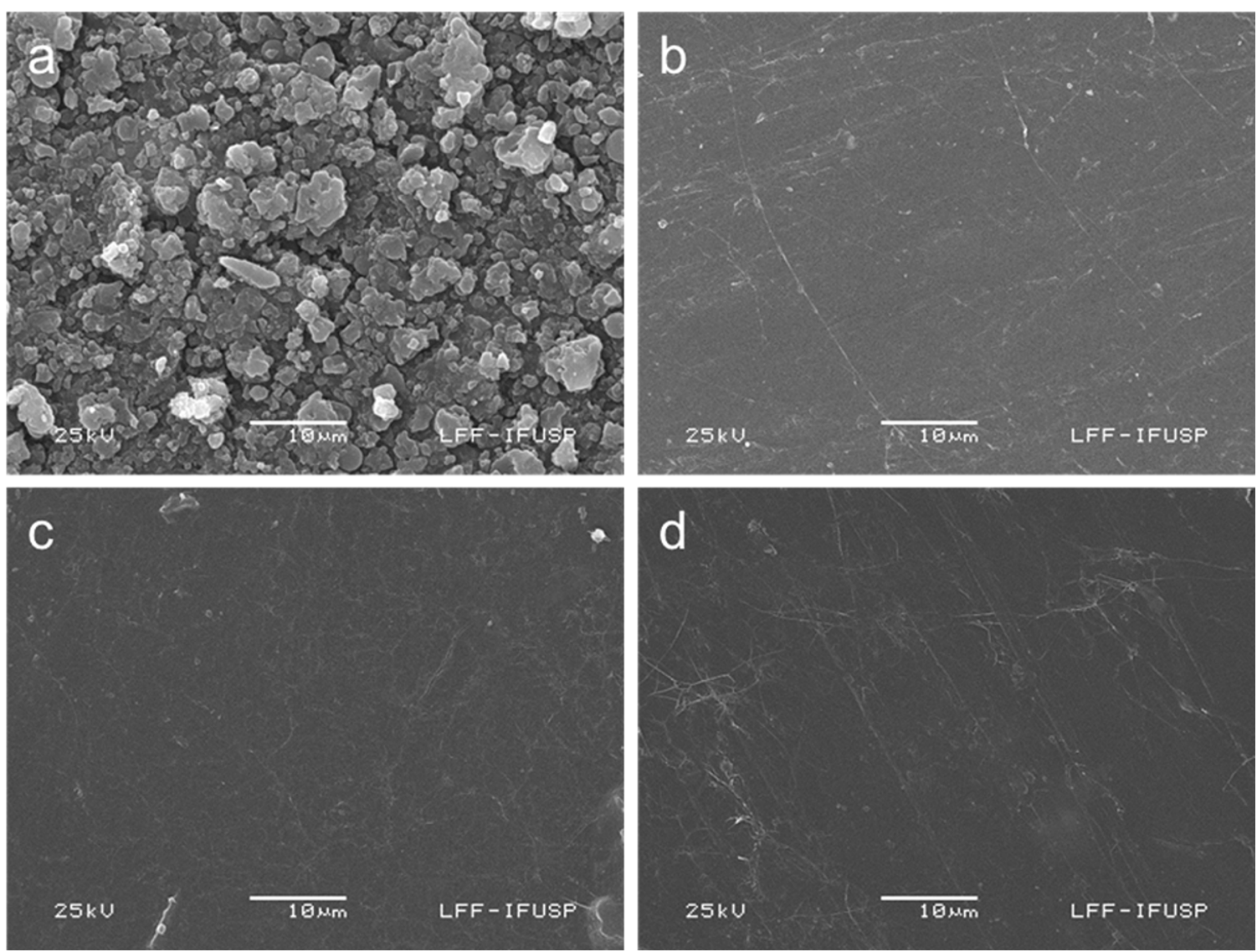

Figure 4. Micrographs showing (a) irregular colloidal shape of AC_KL and fractured surfaces of (b) PP, (c) PP_AC_2 and (d) PP_AC_5

\section{Conclusions}

PP_KL composites were obtained, and the effects of $\mathrm{KL}$ incorporation on practical adhesion were investigated. $\mathrm{KL}$ incorporation increased the surface energy of pristine and CDT-treated samples. CDT-treated samples showed the highest surface energy values with $2 \mathrm{wt} \%$ of $\mathrm{KL}$, while the highest peeling strength was obtained for specimens with $1 \mathrm{wt} \%$ of KL. A synergistic effect of KL and CDT was observed. The surface energy changes are not related to changes in the PP crystallinity index. PP and KL phase separation was not observed in SEM micrographs. KL addition improved the practical adhesion of PP films and increased the efficiency of CDT.

\section{Acknowledgements}

The authors thank $\mathrm{CNPq}$ (National Counsel of Technological and Scientific Development) for financial support (CNPq process: $163369 / 2015-1$ ) and the Multiuser Central Facilities (UFABC) for the experimental support.

\section{References}

1. Sellin N, Campos JSC. Surface composition analysis of PP films treated by corona discharge. Materials Research. 2003;6(2):163166.

2. Simão JA, Carmona VB, Marconcini JM, Mattoso LHC, Barsberg SC, Sanadi AR. Effect of Fiber Treatment Condition and Coupling Agent on the Mechanical and Thermal Properties in Highly Filled Composites of Sugarcane Bagasse Fiber/PP. Materials Research. 2016;19(4):746-751.

3. Kalapat N, Amornsakchai T. Surface modification of biaxially oriented polypropylene (BOPP) film using acrylic acid-corona treatment: Part I. Properties and characterization of treated films. Surface and Coatings Technology. 2012;207:594-601.

4. Sanchis MR, Blanes V, Blanes M, Garcia D, Balart R. Surface modification of low density polyethylene (LDPE) film by low pressure O2 plasma treatment. European Polymer Journal. 2006;42(7):1558-1568.

5. Dowding C, Dowding R, Franceschini F, Griffiths J. The Effect of laser Power, Traverse Velocity and Spot Size on the Peel Resistance of a Polypropylene/Adhesive Bond. Packaging Technology and Science. 2015;28(7):621-632. 
6. Akishev Y, Grushin M, Napartovich A, Trushkin N. Novel AC and DC Non-Thermal Plasma Sources for Cold Surface Treatment of Polymer Films and Fabrics at Atmospheric Pressure. Plasmas and Polymers. 2002;7(3):261-289.

7. Kusano Y. Atmospheric Pressure Plasma Processing for Polymer Adhesion: A Review. The Journal of Adhesion. 2014;90(9):755777.

8. Izdebska J. Corona Treatment. In: Izdebska J, Thomas S. Printing on Polymers - Fundamentals and Applications. Norwich, NY, Willian Andrew; 2016. p. 123-142.

9. Temmerman E, Akishev Y, Trushkin N, Leys C, Verschuren J. Surface modification with a remote atmospheric pressure plasma: dc glow discharge and surface streamer regime. Journal of Physics D: Applied Physics. 2005;38(4):505-509.

10. Kurusu RS, Demarquette NR. Surface properties evolution in electrospun polymer blends by segregation of hydrophilic or amphiphilic molecules. European Polymer Journal. 2017;89:129137.

11. Geoghegan M, Krausch J. Wetting at polymer surfaces and interfaces. Progress in Polymer Science. 2003;28(2):261-302.

12. Peng Y, Liu R, Cao J. Characterization of surface chemistry and crystallization behavior of polypropylene composites reinforced with wood flour, cellulose, and lignin during accelerated weathering. Applied Surface Science. 2015;332:253-259.

13. Mahmood N, Yuan Z, Schmidt J, Xu C. Depolymerization of lignins and their applications for the preparation of polyols and rigid polyurethane foams: A review. Renewable and Sustainable Energy Reviews. 2016;60:317-329.

14. Poletto M, Zattera AJ. Materials produced from plant biomass: part III: degradation kinetics and hydrogen bonding in lignin. Materials Research. 2013;16(5):1065-1070.

15. Gouveia JR, Costa CL, Tavares LB, Santos DJ. Synthesis of Lignin-Based Polyurethanes: A Mini-Review. Mini-Reviews in Organic Chemistry. 2019;16(4):345-352.

16. Laurichesse S, Avérous L. Chemical modification of lignins: Towards biobased polymers. Progress in Polymer Science. 2014;39(7):1266-1290.

17. Wang C, Kelley SS, Venditti RA. Lignin-Based Thermoplastic Materials. ChemSusChem. 2016;9(8):770-783.

18. Chakar FS, Ragauskas AJ. Review of current and future softwood kraft lignin process chemistry. Industrial Crops and Products. 2004;20(2):131-141.

19. AL-Oqla FM, Sapuan SM. Polymer Selection Approach for Commonly and Uncommonly Used Natural Fibers Under Uncertainty Environments. JOM. 2015;67(10):2450-2463.

20. AL-Oqla FM, Sapuan SM, Ishak MR, Nuraini AA. Decision making model for optimal reinforcement condition of natural fiber composites. Fibers and Polymers. 2015;16(1):153-163.

21. AL-Oqla FM, Sapuan SM, Jawaid M. Integrated MechanicalEconomic-Environmental Quality of Performance for Natural Fibers for Polymeric-Based Composite Materials. Journal of Natural Fibers. 2016;13(6):651-659.
22. AL-Oqla FM, Salit MS, Ishak MR, Aziz NA. Selecting Natural Fibers for Bio-Based Materials with Conflicting Criteria. American Journal of Applied Sciences. 2015;12(1):64-71.

23. Almagableh A, Al-Oqla FM, Omari MA. Predicting the Effect of nano-Structural Parameters on the Elastic Properties of Carbon Nanotube-Polymeric Based Composites. International Journal of Performability Engineering. 2017;13(1):73-86.

24. Al-Oqla FM, Sapuan SM. Investigating the Inherent Characteristic/ Performance Deterioration Interactions of Natural Fibers in Bio-Composites for Better Utilization of Resources. Journal of Polymers and the Environment. 2018;26(3):1290-1296.

25. AL-Oqla FM. Investigating the mechanical performance deterioration of Mediterranean cellulosic cypress and pine/ polyethylene composites. Cellulose. 2017;24(6):2523-2530.

26. Ito NM, Nacas AM, Antunes RA, Salvadori MC, dos Santos DJ. Study of the correlation between flexible food packaging peeling resistance and surface composition for aluminummetallized BOPP films aged at $60^{\circ} \mathrm{C}$. The Journal of Adhesion. 2017;93(1-2):4-17.

27. Azadfar M, Hiscox WC, Chen S. Solubilization of lignin in copolymer micelles in aqueous solution. Colloids and Surfaces A: Physicochemical and Engineering Aspects. 2016;503:1-10.

28. Nacas AM, Ito NM, de Sousa RR, Spinacé MA, dos Santos DJ. Effects of $\mathrm{NCO}: \mathrm{OH}$ ratio on the mechanical properties and chemical structure of kraft lignin-based polyurethane adhesive. The Journal of Adhesion. 2017;93(1-2):18-29.

29. Brandrup J, Immergut EH, Grulke EA, eds. Polymer Handbook. 4th ed. New York: John Wiley \& Sons; 1999.

30. Kun D, Pukánszky B. Polymer/lignin blends: Interactions, properties, applications. European Polymer Journal. 2017;93:618641.

31. Sen S, Patil S, Argyropoulos DS. Thermal properties of lignin in copolymers, blends, and composites: a review. Green Chemistry. 2015;17(11):4862-4887.

32. Sahoo S, Misra M, Mohanty AK. Enhanced properties of lignin-based biodegradable polymer composites using injection moulding process. Composites Part A: Applied Science and Manufacturing. 2011;42(11):1710-1718.

33. Weihua K, He Y, Asakawa N, Inoue Y. Effect of lignin particles as a nucleating agent on crystallization of poly(3-hydroxybutyrate). Journal of Applied Polymer Science. 2004;94(6):2466-2474.

34. Chen F, Dai H, Dong X, Yang J, Zhong M. Physical properties of lignin-based polypropylene blends. Polymer Composites. 2011;32(7):1019-1025.

35. Sugano-Segura ATR, Tavares LB, Rizzi JGF, Rosa DS, Salvador MC, dos Santos DJ. Mechanical and thermal properties of electron beam-irradiated polypropylene reinforced with Kraft lignin. Radiation Physics and Chemistry. 2017;139:5-10.

36. Tavares LB, Ito NM, Salvadori MC, dos Santos DJ, Rosa DS. $\mathrm{PBAT} / \mathrm{kraft}$ lignin blend in flexible laminated food packaging: Peeling resistance and thermal degradability. Polymer Testing. 2018;67:169-176. 